\title{
Effects of stria terminalis sections on locomotor, avoidance, and alternation behavior in rats
}

\author{
TROND MYHRER \\ Institute of Neurophysiology, University of Oslo, Oslo, Norway
}

\begin{abstract}
In a previous study, differential behavioral effects between medial and lateral fimbrial lesions were seen. However, since the lateral fimbrial lesions comprised the stria terminalis and the medial fimbrial lesions did not, it seemed important to know the effects of selective division of the stria in the same behavioral tests. The present results show that section of the stria in rats improved two-way active avoidance performance, whereas the behavior in open field, passive avoidance, and spontaneous alternation tests was not significantly changed. Thus, a reservation must be taken into account with regard to the finding that lateral fimbrial lesions improve two-way active avoidance behavior. The results of stria terminalis sections are discussed in terms of a functional differentiation within the amygdaloid complex.
\end{abstract}

In a recent study, it was suggested that the fimbrial output from the dorsal and the ventral hippocampus may subserve different behavioral functions due to different projection fields (Myhrer, 1975). The findings were improved passive avoidance and impaired two-way active avoidance behavior in rats with the medial fimbria lesioned, whereas damage to the lateral fimbria produced no effect in passive avoidance but improved active avoidance performance. Only lateral fimbrial lesions resulted in changes in open field and spontaneous alternation behavior. However, since the stria terminalis was disrupted concomitantly with the lateral fimbrial lesions and left undamaged by the medial lesions, it appears pertinent to investigate what may follow selective division of the stria in the same behavioral tests. In the present study, the subjects were run in open field, passive and active avoidance, and spontaneous alternation tests.

The stria terminalis in the rat links the corticomedial nuclear group of the amygdala directly with the ipsilateral medial hypothalamus and with the telencephalic formations in both hemispheres (cf. de Olmos, 1972). Since the basolateral nuclei primarily project through the ventral amygdalofugal pathways (cf. de Olmos, 1972), it appears justified, from a functional point of view, to compare division of the stria with damage to the corticomedial nuclei.

In view of the sparse literature on behavioral effects of selective corticomedial lesions, hypotheses of what may follow transection of the stria terminalis are not easily advanced. However, corticomedial lesions have been reported to cause passive avoidance deficit in cats (Ursin, 1965) and rats (Pellegrino, 19.68), but not in mice (Slotnick \& McMullen, 1973). Furthermore, no effects have been observed in the open field test and in the shuttlebox in rats (Sclafani, Belluzzi, \& Grossman,

This study was supported by the Norwegian Research Council for Science and the Humanities.
1970). Inasmuch as amygdaloid ablations produce alimentary changes (cf. Kaada, 1972), the body weight was recorded pre- and postoperatively in the present study.

\section{METHOD}

\section{Subjects}

Twenty-eight male albino rats of the Moll-Wistar strain, weighing $280-300 \mathrm{~g}$ at the time of surgery were randomly assigned to three groups; 10 rats received bilateral section of the stria terminalis, 10 received bilateral neocortical lesions, and 8 served as intact controls. The subjects were housed in groups of three and fed commercial rat pellets and water ad lib, except when deprived. Rats from different groups were housed together, and their group assignment was not known during testing.

\section{Surgery}

The rats were anesthetized with pentobarbital sodium. A stereotaxic instrument was used as head holder. After suitable openings were made in the skull, the dura was opened, and the neocortex and the corpus callosum overlying the septal end of the fimbria were aspirated. In this way, a portion of the stria terminalis became visible in the operation microscope used. In the experimental group, it was intended to squeeze off the stria with thin watchmaker's forceps without damaging the fimbria. Correspondent exposure of the stria was made in the neocortically lesioned control group. The normal control subjects were given an incision in the scalp only.

Upon completion of testing, the brains were removed, fixed in Formalin, and embedded in paraffin. Sixteen micron-thick sections were prepared, and every 20 th section was stained with thionin.

\section{Open Field}

Apparatus. The open field consisted of an enclosed wooden chamber $(96 \times 96 \times 73 \mathrm{~cm})$ with a pyramidal-shaped top. The floor was marked off into 36 equal squares. A startbox $(22 \times 14 \times 9 \mathrm{~cm})$ was placed in one corner. Illumination was provided by a $40-\mathrm{W}$ bulb located in the apex of the enclosure.

Procedure. The rats were tested individually for $2 \mathrm{~min}$ each day for 4 consecutive days. Three measures were made in this situation: (a) The startbox exit latency. (b) The number of squares traversed (in the entire and the interior of the field). 

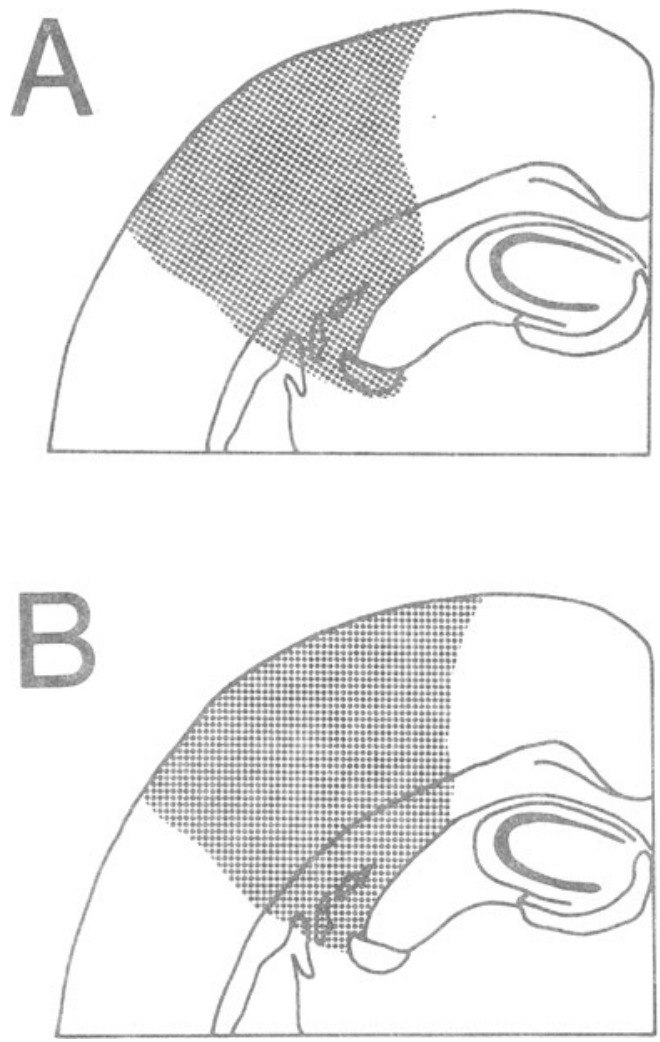

Figure 1. Reconstruction of a representative stria terminalis lesion (A) and a neocortical lesion (B).

(c) The number of fecal boluses dropped. The testing started on Postoperative Day 14.

\section{Passive Avoidance}

Apparatus. Testing took place in a box $(50 \times 52 \times 23 \mathrm{~cm})$, previously described in detail (Myhrer, 1975). Briefly, a grid floor was wired to one terminal of an electric source, and the other one was connected to a water dish. Whenever the rat touched the water, it closed the circuit and received a shock of $.35 \mathrm{~mA}$.

Procedure. The subjects were deprived of water for $48 \mathrm{~h}$ and tested from Postoperative Day 23. In the test box, the rats were permitted to drink from the water dish during a total period of $2 \mathrm{~min}$. They were then placed in the opposite corner from the dish, which at the same time became electrified for a test period of $15 \mathrm{~min}$. The total number of shocks accepted by the rats was recorded.

\section{Active Avoidance}

Apparatus. Testing was performed in a shuttlebox $(40 \times 22 \times 20 \mathrm{~cm})$, described elsewhere (Myhrer, 1975). Compartment grids could be independently electrified by a shocker-scrambler adjusted to $.5 \mathrm{~mA}$.

Procedure. On the $1 \mathrm{st}$ day, the rats were allowed to explore the box for $5 \mathrm{~min}$, following which 20 trials were given daily for 3 consecutive days. The CS was a continuously sounded buzzer. The CS-US interval was $10 \mathrm{sec}$, and both buzzer and shock stayed on until the rat escaped to the nonelectrified side, but no longer than $20 \mathrm{sec}$. The intertrial interval was $35 \mathrm{sec}$. Crossings between trials were recorded but not punished. The testing began 28 days following surgery.

\section{Spontaneous Alternation}

Apparatus. A standard unbaited T maze (length of alleys $50 \mathrm{~cm}$ ) previously described in detail (Myhrer, 1975) was used. One goal arm was black, the other white, and the start arm was gray.

Procedure. Prior to testing, the subjects were handled systematically, being allowed to explore a wooden board $(120 \times 60 \mathrm{~cm}) 3 \mathrm{~min}$ for 7 days. Testing was carried out on Postoperative Day 44 and consisted of two trials in the T maze. The rats were placed in the main alley, and, after entering one of the goalboxes, they were placed on the handling board for $1 \mathrm{~min}$ before being returned for the next trial. The alternation test was employed after the other tests had been completed since the handling procedure associated with this test may mask lesion effects in open field and active avoidance (Myhrer, unpublished observations).

\section{RESULTS}

\section{Histology}

In all 10 rats from the experimental group, $80 \%-100 \%$ of the stria terminalis was sectioned bilaterally (Figure 1A). No damage, or only slight (less than 10\%) damage, to the fimbria was observed among these subjects. In all 10 rats from the lesioned control group, the neocortex corresponding to the Areas 1, 2, and 3 (Krieg, 1946), portions of the corpus callosum, the dorsal striatum and intervening white matter were destroyed bilaterally (Figure 1B). Corresponding lesions were also seen in the experimental animals.

\section{Body Weight}

As seen from Figure 2, both lesioned groups lost body weight after the operation. They did not obtain preoperative level until 9-11 days following surgery. When the weight of Postoperative Day 4 was chosen as a representative sample, analysis of variance revealed a reliable treatment effect $(F=14.56, \mathrm{df}=2 / 25, \mathrm{p}<.01)$. Mean comparisons with two-tailed $t$ test showed that both the experimental group and the lesioned control group differed significantly $(\mathrm{p}<.001)$ from the normal group. The lesioned groups did not differ reliably from one another.

\section{Open Field Behavior}

Analysis of variance revealed no significant differences

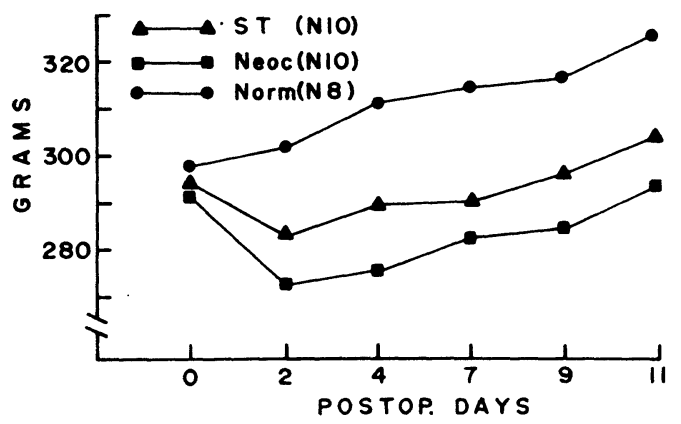

Figure 2. Mean postoperative body weight. Abbreviations for this and following figures: ST $=$ stria terminalis; neoc $=$ neocortical norm $=$ normal. 
Table 1

Means and Standard Errors of Open-Field Responses Based on Average Scores for 4 Days

\begin{tabular}{lccccc}
\hline Group & $\mathrm{N}$ & $\begin{array}{c}\text { Startbox Exit } \\
\text { Latency (Sec) }\end{array}$ & \multicolumn{2}{c}{$\begin{array}{c}\text { Number of Squares } \\
\text { Entire Field }\end{array}$} & $\begin{array}{c}\text { Traversed in } \\
\text { Interior Field }\end{array}$ \\
\hline ST & 10 & $64.5 \pm 52.8$ & $13.4 \pm 17.5$ & $1.7 \pm 3.7$ & Fecal Boluses \\
Neocort & 10 & $51.8 \pm 42.5$ & $13.6 \pm 17.4$ & $1.4 \pm 1.6$ & $2.5 \pm 2.2$ \\
Normal & 8 & $62.6 \pm 33.3$ & $8.1 \pm 8.5$ & $.4 \pm .5$ & $2.0 \pm 1.5$ \\
\hline
\end{tabular}

among the groups in the startbox exit latency, locomotor activity in the entire or the interior of the field or defecation scores (Table 1).

\section{Passive Avoidance}

Analysis of variance revealed no significant differences in the number of shocks accepted among the groups (Figure 3).

\section{Active Avoidance}

The experimental group displayed improved shuttlebox performance (Figure 4A). Analysis of variance based on the total number of avoidance responses yielded a reliable treatment effect $(F=7.53$, $\mathrm{df}=2 / 25, \mathrm{p}<.01)$. Mean comparisons with two-tailed $t$ test showed that the experimental group differed significantly from both the normal group $(t=3.39$, $\mathrm{p}<.01)$ and the lesioned control group $(\mathrm{t}=2.50$, $\mathrm{p}<.05)$. The control groups did not differ reliably from one another. Analysis of variance showed no significant differences in the total number of intertrial crossings among the groups (Figure 4B). However, a significant all over effect emerged on Day 1 of testing $(F=4.34$, $\mathrm{df}=2 / 25, \mathrm{p}<.025)$. Mean comparisons revealed that the experimental group made significantly more intertrial crossings on Day 1 than both control groups $(2 \mathrm{p}<.05)$. The control groups did not differ significantly from one another.

\section{Spontaneous Alternation}

No substantial differences in the rate of spontaneous alternation occurred. The percentage of alternation

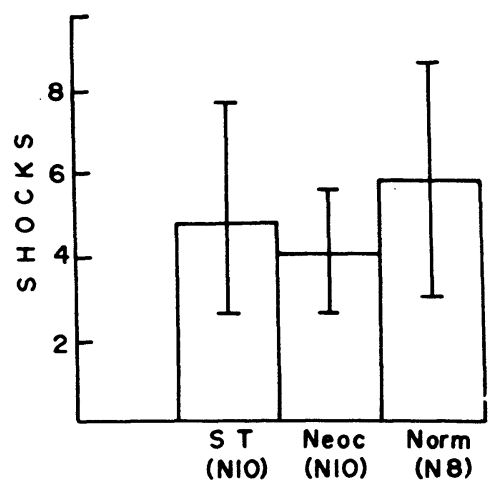

Figure 3. Mean number of shock responses in passive avoidance test. Bars represent \pm SEM. among the groups was the following: experimental, $70 \%$; neocortical, $70 \%$; and normal, $87 \%$.

\section{DISCUSSION}

Transection of the stria terminalis produced improved active avoidance performance, whereas open field, passive avoidance, and spontaneous alternation behavior remained unaffected. The postoperative body weight was not significantly different between the experimental animals and the lesioned control subjects.

In view of the present data, the improved active avoidance seen after lateral fimbrial lesions (see the introduction) may be attributed to concomitant damage to the stria terminalis. What may follow selective transection of the lateral fimbria in the shuttlebox situation remains to be investigated. Accordingly, at least one serious reservation must be taken into account, when it is suggested that the fimbrial output from the dorsal and the ventral hippocampus may subserve different functions.

The improved shuttlebox behavior following stria
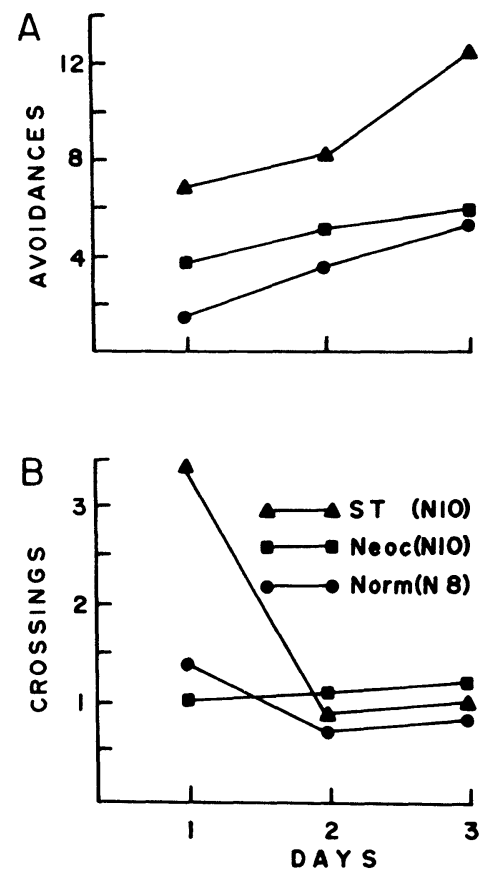

Figure 4. Mean number of active avoidance responses (A) and intertrial crossings (B). 
sections does not harmonize with unchanged performance in the same test after corticomedial lesions (Sclafani et al., 1970). However, in the latter study, the testing started as late as 4 months postoperatively. Therefore, the lack of effect might very well be due to recovery of function (cf. Rosner, 1970).

The intact passive avoidance in the present study stands in contrast to the passive avoidance deficit seen in cats with corticomedial lesions (Ursin, 1965). These contradictions may probably be more due to situational and procedural differences than to species differences (cf. Coover, Ursin, \& Levine, 1973). However, the present findings gain support from the lack of passive avoidance deficit in mice (Slotnick \& McMullen, 1973). Furthermore, corticomedial lesions produce only a slight passive avoidance deficit in rats compared with the pronounced deficit obtained after basolateral ablations (Pellegrino, 1968).

Normal locomotor open field behavior has also been observed in rats with corticomedial damage (Sclafani et al., 1970). As with the body weight, it may be suggested that the additional lesions masked possible alimentary changes after stria sections. This argument has a certain relevance inasmuch as interference with the striatum may produce aphagia and adipsia (cf. Levine \& Schwartzbaum, 1973). On the other hand, Sclafani et al. (1970) report that corticomedial lesions in rats did not affect ad-lib food or water intake in the home cage.

The present results may give further support to the notion of a functional differentiation within the amygdaloid complex (cf. Kaada, 1972). The improved shuttlebox performance following stria lesions contrasts the impaired shuttlebox behavior in rats with basolateral ablations (Bush, Lovely, \& Pagano, 1973; Coover et al., 1973). Furthermore, transection of the stria terminalis did not result in altered passive avoidance or open field behavior, whereas basolateral lesions produce passive avoidance deficit (Pellegrino, 1968; Coover et al., 1973) and less immobility in the open field (Coover et al., 1973).
It has been suggested that basolateral lesions may reduce fear in rats (Coover et al., 1973). If damage to the corticomedial nuclei or the stria terminalis has the opposite effect, the possible increase in fear is presumably a very slight one, only revealed in a strongly fear provoking test situation like the shuttlebox.

\section{REFERENCES}

Bush, D. F., Lovely, R. H. \& Pagano, R. R. Injection of ACTH induces recovery from shuttle-box avoidance deficits in rats with amygdaloid lesions. Journal of Comparative and Phy siological Psy chology, 1973, 83, 168-172.

Coover, G., Ursin, $\mathbf{H}_{\circ}$, \& Levine, S. Corticosterone and avoidance in rats with basolateral amygdala lesions. Journal of Comparative and Phy siological Psychology, 1973, 85, 111-122.

de Olmos, J. S. The amygdaloid projection field in the rat as studied with the cupric-silver method. In B. E. Eleftheriou (Ed.), The neurobiology of the amygdala. New York-London: Plenum Press, 1972. Pp. 145-204.

Kaada, B. R. Stimulation and regional ablation of the amygdaloid complex with reference to functional representations. In B. E. Eleftheriou (Ed.), The neurobiology of the amygdala. New York-London: Plenum Press, 1972. Pp. 205-281.

Krieg, W. J. S. Connections of the cerebral cortex: I. The albino rat: A. Topography of the cortical areas. Journal of Comparative Neurology, 1946, 84, 221-275.

Levine, M. S., \& Schwartzbaum, J. S. Sensorimotor functions of the striatopallidal system and lateral hypothalamus and consummatory behavior in rats. Joumal of Comparative and Phy siological Psy chology, 1973, 85, 615-636.

Myhrer, T. Locomotor, avoidance and maze behavior in rats with selective disruption of hippocampal output. Journal of Comparative and Phy siological Psy chology, 1975, in press.

Pellegrino, L. Amygdaloid lesions and behavioral inhibition in the rat. Journal of Comparative and Phy siological Psychology, $1968,65,483-491$.

Rosner, B. S. Brain functions. Annual Review of Psychology, $1970,21,555-594$

Sclafani, A., Belluzzi, J. D., \& Grossman, S. P. Effects of lesions in the hypothalamus and amygdala on feeding behavior in the rat. Journal of Comparative and Physiological Psychology, $1970,72,394-403$.

Slotnick, B. M., \& McMullen, M. F. Response inhibition deficits in mice with septal, amygdala, or cingulate cortical lesions. Phy siology and Behavior, 1973, 10, 385-389.

Ursin, H. Effects of amygdaloid lesions on avoidance behavior and visual discrimination in cats. Experimental Neurology, 1965, 11, 298-317.

(Received for publication December 30, 1974; accepted February 21,1975 .) 